\title{
Synergistic Effect of DBP with CTAB on Flotation Separation of Quartz from Collophane
}

\author{
Zhongxian $\mathrm{Wu}^{1,2}{ }^{1}$, Dongping Tao ${ }^{1, *}$, Patrick Zhang ${ }^{3}{ }^{\mathbb{D}}$, Xiaojun Jiang ${ }^{2}$ and Man Jiang ${ }^{1}$ \\ 1 School of Resources and Environmental Engineering, Shandong University of Technology, \\ Zibo 255049, China; wuzhongxian567@163.com (Z.W.); jiangman@sdut.edu.cn (M.J.) \\ 2 School of Mining Engineering, University of Science and Technology Liaoning, Anshan 114051, China; \\ anshanjiangxj@163.com \\ 3 Florida Industrial and Phosphate Research Institute, Florida Polytechnic University, Bartow, FL 33830, USA; \\ jzhang@flpoly.org \\ * Correspondence: daniel.dtao@gmail.com; Tel.: +86-13813467505
}

Citation: Wu, Z.; Tao, D.; Zhang, P.; Jiang, X.; Jiang, M. Synergistic Effect of DBP with CTAB on Flotation Separation of Quartz from Collophane. Minerals 2021, 11, 1196. https:// doi.org/10.3390/min11111196

Academic Editor: Saeed Chehreh Chelgani

Received: 28 September 2021

Accepted: 25 October 2021

Published: 28 October 2021

Publisher's Note: MDPI stays neutral with regard to jurisdictional claims in published maps and institutional affiliations.

Copyright: () 2021 by the authors. Licensee MDPI, Basel, Switzerland. This article is an open access article distributed under the terms and conditions of the Creative Commons Attribution (CC BY) license (https:// creativecommons.org/licenses/by/ $4.0 /)$.

\begin{abstract}
Collophane is difficult to upgrade by reverse flotation of quartz with amine collector alone due to its low grade, complex structure, fine dissemination grain size, etc. This investigation was conducted to explore the synergistic effect of dibutyl phthalate (DBP) as a surfactant with cetyltrimethyl ammonium bromide (CTAB) as the collector on the separation of quartz from collophane by means of micro-flotation tests, surface tension and aggregate size measurements, and froth water mass fraction/recovery characterization. It was found that DBP reduced the surface tension of the reagent solution and enhanced the collision probability between bubbles and quartz particles by increasing the size of aggregates through increased hydrophobic interaction between the quartz particles and DBP droplets. The addition of DBP reduced the entrainment of fine collophane particles as a result of improved defoaming and increased the flotation recovery of quartz without resulting in any flotation of collophane at dosages lower than $200 \mathrm{mg} / \mathrm{L}$. Flotation test results with the binary artificial mineral mixture showed that DBP improved the $\mathrm{P}_{2} \mathrm{O}_{5}$ recovery, $\mathrm{SiO}_{2}$ rejection, and $\mathrm{P}_{2} \mathrm{O}_{5}$ grade by up to $7 \%$, $12 \%$, and $1 \%$, respectively.
\end{abstract}

Keywords: quartz; collophane; DBP; silicon removal reagent; aggregation; entrainment

\section{Introduction}

Phosphate rock plays an important role in China's national economy and collophane accounts for about 75\% of the world's total phosphate rock reserves [1]. China is the second largest phosphate rock resource country in the world with 3.2 billion tons of phosphate rock resources [2]. Sedimentary collophane accounts for more than $80 \%$ of the total phosphate reserve and siliceous and magnesian collophane accounts for about half of the total with the majority being low and middle grade ore [3]. Therefore, lowand middle-grade siliceous and magnesian collophane is the main object of research in the field of phosphate rock separation in China. The phosphorus in collophane mainly exists in the form of ultrafine fluorapatite, which is a colloidal fine aggregate and is closely associated with gangue minerals such as dolomite and quartz, etc. [4]. With the continuous exploitation and utilization of phosphate rock resources, collophane ores have nowadays been characterized by low grade, complex structure, fine dissemination grain size and difficult dissociation [5], which makes fine grinding necessary to liberate gangue minerals from the phosphate matrix. A typical collophane flotation feed contains approximately $90 \%$ fine particles smaller than $74 \mu \mathrm{m}$ in size, making it very difficult to upgrade by flotation. Over the past decades, low- and medium-grade siliceous collophane has been commonly desiliconized by reverse flotation but the concentrate often contains a high content of $\mathrm{SiO}_{2}$ due to lack of effective flotation technology [6]. This leads to the increase in production of phosphogypsum by-product and threatens the sustainability of the wet-process phosphoric 
acid industry. Therefore, it is imperative to develop a more efficient reverse flotation process for collophane desilication.

Flotation is the most effective beneficiation process for phosphate ores and more than $60 \%$ of the phosphate concentrate products in the world are obtained by flotation [1] The collector plays an important role in the flotation process and cationic amine collectors are often used for desilication of collophane by reverse flotation [6-11]. Primary fatty amines $\left(\mathrm{R}-\mathrm{NH}_{2}\right)$, quaternary ammonium salts $\left(\mathrm{R}-\mathrm{N}\left(\mathrm{CH}_{3}\right)_{3}\right)$, and alkyl ether monoamines $(\mathrm{R}-$ $\left.\mathrm{O}-\left(\mathrm{CH}_{2}\right)_{3}-\mathrm{NH}_{2}\right)$ have been proven to be effective collectors for desilication and are widely used. They have significant collecting ability for quartz and relatively good selectivity against collophane [10]. Unfortunately, these three types of collectors contain a similar hydrophobic group in their molecule and do not show substantial difference in flotation performance. Vieira and Peres [11] investigated the effect of particle size on the floatability of quartz using dodecylamine as collector and concluded that the quartz flotation recovery decreased sharply with the decrease of particle size. Sobhy et al. [12] and Tao and Sobhy [13] proved that the main reason why gangue minerals are not effectively removed in desilication of hematite by reverse flotation is the low collision probability between fine quartz particles and conventional bubbles. In addition, $\mathrm{Wu}$ and Tao [14] studied the process mineralogy of collophane from Yunnan, China and its desilication difficulties by double reverse flotation. They demonstrated that fine collophane particles were entrained in the flowing fluid around bubbles, reducing the concentrate $\mathrm{P}_{2} \mathrm{O}_{5}$ recovery. In view of the above knowledge of flotation of fine collophane particles, a more potent collector for quartz alone will not solve the problem of poor separation performance with collophane.

In recent years, it has been shown that oil-assisted flotation technology is more effective for flotation of quartz, coal, hematite, talc, and other minerals than the conventional flotation process without nonpolar oil [15-17]. In this process, tiny oil droplets formed by intense stirring preferentially adhere and spread on the hydrophobic particle surface, resulting in coverage of the oil layer and higher hydrophobicity [18]. With oil-assisted flotation a similar hydrophobicity can be achieved at a lower collector dosage, compared to conventional flotation. The addition of non-polar oils often results in larger aggregate size, faster flotation rate, less gangue mineral entrainment, lower collector dosage, and higher concentrate grades and recoveries [16]. The interactions between the oil and the mineral particle surface mainly depend on an oil bridging effect caused by hydrophobic interactions, which is similar to the interaction of kerosene with coal, graphite, molybdenite, and natural gold. For natural hydrophilic minerals, the addition of collectors to alter mineral surface wettability is necessary before the oil interacts with the mineral particle surface. Hydrophobic particles bridged together by oil droplets grow into larger aggregates, thus improving the collection probability between fine particles and bubbles [19]. The first-order reaction rate equation of flotation kinetics shows that improving collecting probability is an effective way to increase the flotation rate constant [20]. The application of non-polar oils to mineral flotation processes is considered a promising technique to enhance flotation performance, particularly for refractory and finely disseminated minerals.

Nevertheless, it has not been demonstrated if non-polar oils are capable of improving the desilication performance of collophane by reverse flotation. Kerosene is used in most of the reported studies of oil-assisted flotation. In this study DBP with similar physical and chemical properties to kerosene was employed in attempts to understand its synergistic effects with CTAB used as the collector on the flotation separation performance of quartz from collophane. DBP is characterized by high viscosity and mainly used as plasticizer in polyvinyl chloride [21]. Its high viscosity may enhance the stability of DBP at the interface based on ensuring the spreading process of the DBP droplet on the surface of the minerals and bubbles [22]. In fact, it has been used as collector in coal flotation [23]. The collecting potency and selectivity of CTAB were evaluated by conducting microflotation tests with pure minerals and their artificial mixtures with and without DBP. Furthermore, the synergistic mechanisms of DBP were systematically investigated to understand the differences in observed flotation performance by measuring surface tension, 
aggregate size, water mass fraction, and recovery in froth. The results from this study are of great significance to the efficient utilization of low- and middle-grade siliceous collophane resources.

\section{Experimental}

\subsection{Acquisition of Minerals and Reagents}

The pure quartz and collophane (fluorapatite) minerals were acquired from a phosphate mine of Yunnan Yuntianhua Co., Ltd, in Kunyang Town, Jinning District, Kunming City, Yunnan Province, China. The hand-picked samples of pure quartz and collophane minerals were crushed using a roller crusher $($ XPC- $200 \times 125$, Wuhan Exploration Machinery Plant, Wuhan, China) and ground to approximately $74 \mu \mathrm{m}$ using a sealed ceramic mill (BFA, Changchun Keguang Mechanical \& Electrical Co., Ltd, Changchun, China). The ground samples were screened to obtain 38-74 $\mu \mathrm{m}$ size fraction for micro-flotation tests.

Hydrochloric acid and sodium hydroxide with an analytical purity from the National Medicine Group Chemical Reagent Co., Ltd (Beijing, China) were used as $\mathrm{pH}$ regulator. The cationic collector CTAB and nonionic surfactant DBP with an analytical purity of $99.9 \%$ were purchased from the Damao Chemical Reagent Co., Ltd (Tianjing, China). Deionized water with a resistivity $5 \mathrm{M} \Omega / \mathrm{cm}$ and $\mathrm{pH} 7.3$ was used in all experiments.

\subsection{Mineral Sample Characterization}

The chemical compositions of pure minerals were characterized qualitatively by use of an X-ray diffraction (XRD) diffractometer (D8 Advance, Bruker, Billerica, MA, USA) at $40 \mathrm{kV}, 44 \mathrm{~mA}$ and $2^{\circ} / \mathrm{min}$ scan rate. The XRD data of pure minerals were analyzed with HighScore software and the analysis results are shown in Figure 1, which are essentially identical to the standard diffraction peaks of pure quartz and collophane (fluorapatite).
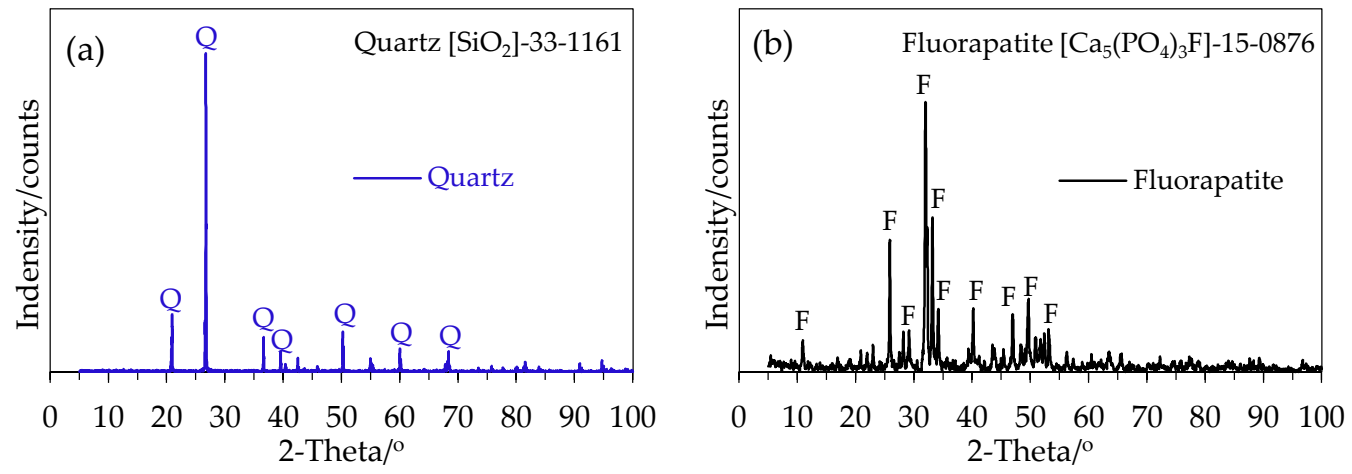

Figure 1. X-ray diffractogram of (a) fluorapatite, (b) quartz.

The multi-element chemical analysis of pure minerals was performed using an X-ray fluorescence spectrometer XRF (Zetium, Malvern Panalytical, Malvern, UK) and the results are shown in Table 1, which indicate that quartz and collophane samples contained $99.37 \%$ $\mathrm{SiO}_{2}$ and $39.56 \% \mathrm{P}_{2} \mathrm{O}_{5}$, respectively. These samples were used as pure minerals in the micro-flotation tests.

Table 1. Multi-element chemical analysis results of pure minerals.

\begin{tabular}{clcccccc}
\hline \multirow{2}{*}{ Quartz } & Name & $\mathrm{SiO}_{2}$ & $\mathrm{Al}_{2} \mathbf{O}_{3}$ & $\mathbf{P}_{\mathbf{2}} \mathbf{O}_{5}$ & $\mathbf{C a O}$ & $\mathbf{F e}_{2} \mathbf{O}_{3}$ & $\mathrm{Cl}$ \\
\cline { 2 - 8 } & Composition (\%) & 99.37 & 0.21 & 0.04 & 0.36 & 0.01 & 0.01 \\
\hline \multirow{2}{*}{ Fluorapatite } & Name & $\mathbf{M g O}$ & $\mathrm{Al}_{\mathbf{2}} \mathbf{O}_{3}$ & $\mathbf{P}_{\mathbf{2}} \mathbf{O}_{5}$ & $\mathbf{C a O}$ & $\mathbf{F e}_{\mathbf{2}} \mathbf{O}_{3}$ & $\mathbf{F}$ \\
\cline { 2 - 8 } & Composition (\%) & 0.08 & 4.2 & 39.56 & 53.35 & 1.69 & 1.12 \\
\hline
\end{tabular}




\subsection{Methods}

\subsubsection{Micro-Flotation Tests}

The floatability of collophane and quartz was investigated by conducting microflotation tests with a small mechanical agitation flotation machine (XFGCII, Guobang Machine Machinery Ltd., Weifang, China) with a volume capacity of $20 \mathrm{~mL}$. Not only can the effect of flotation reagents on the flotation performance of minerals be accurately determined by the flotation machine with a small volume, but also the separation performance with the actual mineral can be simulated with controlled mixtures of pure minerals.

Each micro-flotation test with pure minerals and their artificial mixtures (the mass ratio of collophane and quartz was 6:1) was conducted with $2 \mathrm{~g}$ mineral added into $20 \mathrm{~mL}$ deionized water in the $20 \mathrm{~mL}$ flotation cell and stirred at $1500 \mathrm{rpm}$ for $3 \mathrm{~min}$. Hydrochloric acid or sodium hydroxide solution was added to adjust the slurry $\mathrm{pH}$. The flotation test was initiated and continued for $3 \mathrm{~min}$ after a pre-determined amount of CTAB or the mixture of $\mathrm{CTAB}$ and DBP was added into the pulp and conditioned for $3 \mathrm{~min}$.

The flotation products were separately filtered, dried, and weighed to calculate the flotation recovery. Compared with pure mineral flotation, the flotation products of artificial mixtures were analyzed for $\mathrm{P}_{2} \mathrm{O}_{5}$ and $\mathrm{SiO}_{2}$ grade for performance evaluation. The error bar in the flotation test result represents the standard deviation of the experimental errors. It should be noted that in the presence of DBP, the mixture of DBP and CTAB with a mass ratio of 1:5 was well prepared by ultrasonic treatment prior to its use in the micro-flotation test. This preparation is similar to emulsification and the DBP micro-droplets produced during pretreatment were more dispersible and of smaller size.

\subsubsection{Surface Tension Measurements}

The solution surface tension is an important factor for its surface activity, which is directly related to the collecting performance of the reagents for minerals. Surface tension measurements with $50 \mathrm{~mL} \mathrm{CTAB}$ solutions were carried out after 10 min stirring by use of an automatic surface tensiometer (Sigma 700/701, Biolin Scientific, Biolin, Finland) in the absence and presence of DBP. The platinum plate was burned with the flame of an alcohol lamp to remove the adsorbed reagent prior to each measurement.

\subsubsection{Aggregate Size Measurements}

The aggregation state of hydrophobic quartz particles with and without DBP was studied by employing a laser particle size analyzer (BT-9300S, Bettersize Instrument Ltd., Dandong, China). Each particle size measurement was conducted with $2 \mathrm{~g}$ quartz added into $20 \mathrm{~mL}$ deionized water at $\mathrm{pH} 6.0$ and $5 \mathrm{mg} / \mathrm{L} \mathrm{CTAB}$ concentration and stirred for $3 \mathrm{~min}$.

\subsubsection{Froth Water Mass Fraction Measurements}

The water mass fraction in the froth product is an important characteristic of flotation froth which is closely related to the hydraulic entrainment. Although flotation froth characterization is often performed using bench flotation tests with real ores, successful precedents exist where micro-flotation tests are performed with pure minerals and their mixtures to investigate froth characteristics. Li et al. [24] investigated water mass fraction in the froth as a function of solids concentration and $\mathrm{NaOL}$ dosage for both coarse and fine quartz particles using a micro-flotation column. Li et al. [25] generated flotation froths with different properties through flotation of artificially mixed minerals of chalcopyrite and silica to evaluate the effects of these froth properties on froth rheology.

The water mass fraction of froth was characterized for the effect of CTAB concentration in the absence and presence of DBP. The water mass fraction of froth products in the flotation of artificial mineral mixtures was determined using Equation (1) with the overflowing froth collected for $3 \mathrm{~min}$ after the flotation test was initiated.

$$
\varepsilon=\frac{m_{1}-m_{2}}{m_{1}}
$$


where $\varepsilon$ is the water mass fraction of froth in $\%, m_{1}$ is the weight of initial froth products in grams, $m_{2}$ is the weight of dried froth products in grams.

\section{Results and Discussion}

\subsection{Micro-Flotation Tests}

\subsubsection{Flotation of Pure Minerals}

The floatation recovery of the pure quartz and collophane is shown in Figure 2 as a function of $\mathrm{pH}$ value (left) and as a function of $\mathrm{CTAB}$ concentration (right) in the presence and absence of DBP. It should be noted that collophane did not show any flotation recovery at $5 \mathrm{mg} / \mathrm{L} \mathrm{CTAB}$ concentration with or without DBP over the $\mathrm{pH}$ range between 2 and 12 and therefore no curves are shown for collophane in Figure 2a. The recovery of quartz increased sharply from approximately $10.4 \%$ to nearly $97.8 \%$ when the $\mathrm{pH}$ increased from $\mathrm{pH} 2$ to $\mathrm{pH} 4$ and remained essentially constant over the range of $\mathrm{pH} 4$ to $\mathrm{pH} 10$ beyond which the recovery of quartz decreased dramatically on further increasing the $\mathrm{pH}$ to 12 . The addition of DBP slightly increased the quartz recovery at $\mathrm{pHs}$ lower than 4 or greater than 10 .
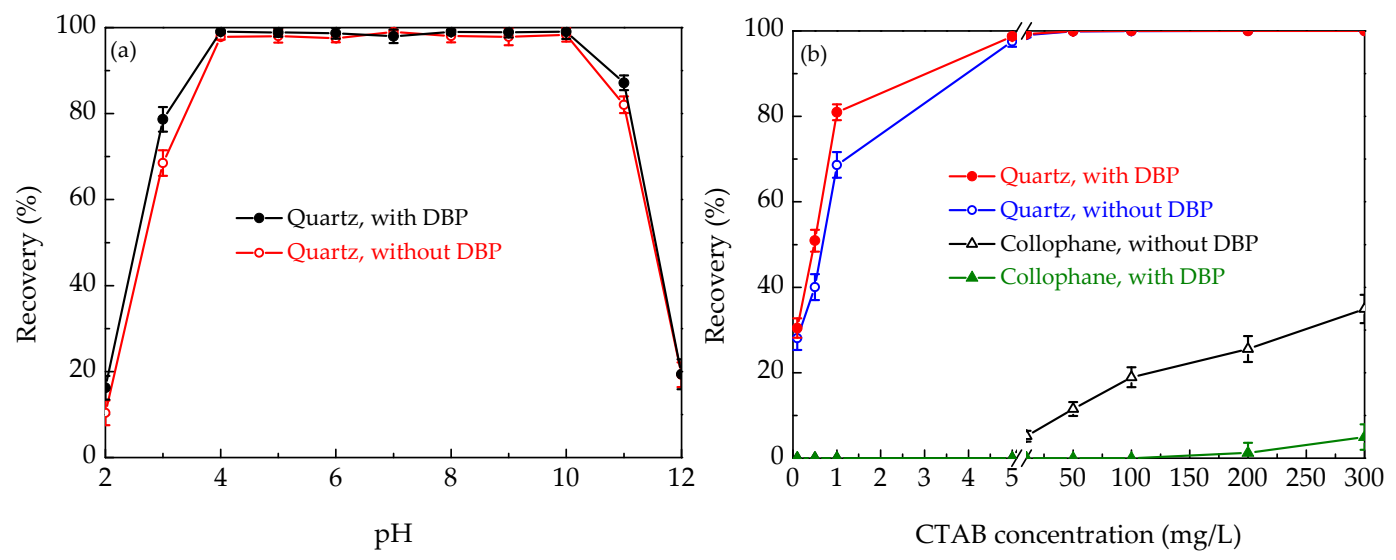

Figure 2. Recovery as a function of $\mathrm{pH}$ at $\mathrm{CTAB}$ concentration of $5.0 \mathrm{mg} / \mathrm{L}$ (a) and as a function of CTAB concentration at pH 6.0 (b) for systems with and without DBP.

Yang et al. [26] measured the zeta potential of magnetite before and after the interaction with $C T A B$ and their data showed that CTAB was always a positively charged ionic species over a wide range of $\mathrm{pH} 2.0$ to 10.0. The zeta potentials of quartz and collophane were found to be negative over the same $\mathrm{pH}$ range and their magnitude increased on increasing the $\mathrm{pH}$ value $[8,27]$. Therefore, CTAB was likely adsorbed on the surface of the quartz and collophane by physical adsorption. The zeta potential measurements performed by Fang et al. [8] provided direct evidence that the selective adsorption of CTAB on the surface of quartz depends on the higher potential of quartz (The zeta potential of quartz is about three times that of collophane at the same $\mathrm{pH}$ ). The low negative charge on the quartz surface at $\mathrm{pH}<4$ resulted in a weak electrostatic adsorption between CTAB and quartz. The negative charge on the quartz surface continuously increased at $\mathrm{pHs}$ greater than 10 . However, the recovery rate of quartz decreased at alkaline $\mathrm{pHs}$ greater than 10 due to the lower concentration of ionic CTAB species [26].

Figure $2 \mathrm{~b}$ shows that the recoveries of both quartz and collophane increased with increasing $\mathrm{CTAB}$ concentration at $\mathrm{pH} 6$, but there were remarkable differences in the flotation recovery of quartz and collophane at a given $\mathrm{CTAB}$ concentration. An increase in CTAB concentration from 0.1 to $5 \mathrm{mg} / \mathrm{L}$ sharply increased the recovery of quartz from $28.1 \%$ to $97.5 \%$ and from $30.5 \%$ to $98.7 \%$ in the absence and presence of DBP, respectively. The use of DBP increased the quartz recovery at CTAB concentrations lower than $5 \mathrm{mg} / \mathrm{L}$. For example, the quartz recovery was approximately $10 \%$ higher in the presence of DBP at a $\mathrm{CTAB}$ concentration of $1 \mathrm{mg} / \mathrm{L}$. A further increase in the CTAB concentration to 
$300 \mathrm{mg} / \mathrm{L}$ showed minimal impacts on the recovery of quartz which remained essentially constant in the absence and presence of DBP. Collophane showed no floatability at CTAB concentrations lower than $5 \mathrm{mg} / \mathrm{L}$. The recovery of collophane increased from $5.2 \%$ to $34.9 \%$ in the absence of DBP and from 0 to $5.0 \%$ in the presence of DBP on increasing the CTAB concentration from 10 to $300 \mathrm{mg} / \mathrm{L}$. The data indicates that DBP showed significant negative effects on collophane recovery, which implies that use of DBP can significantly improve the selectivity of reverse flotation of collophane with CTAB as the collector for quartz.

Fang et al. [8] demonstrated that the adsorption density of ether amine collector on the quartz surface increased with increasing concentration of ether amine collector, whereas the adsorption density on the collophane surface remained relatively low, thus realizing the selective flotation separation. Nevertheless, when the collector concentration was very high, a significant amount of the collector might be adsorbed on collophane, as proposed by Han [9]. It is therefore important to optimize the collector dosage to achieve the optimum separation of quartz from collophane by flotation.

\subsubsection{Flotation of Artificial Mineral Mixtures}

The above single mineral flotation test results indicated the synergistic effect of DBP on the flotation separation of quartz from collophane by use of CTAB as the collector for quartz. To explore the feasibility of applying DBP to quartz-collophane separation by flotation, flotation experiments were performed with the artificial mineral mixture with a mass ratio of collophane to quartz at 6:1 as flotation feed under different CTAB dosages at pH 6.0 and the results are presented in Figure 3.
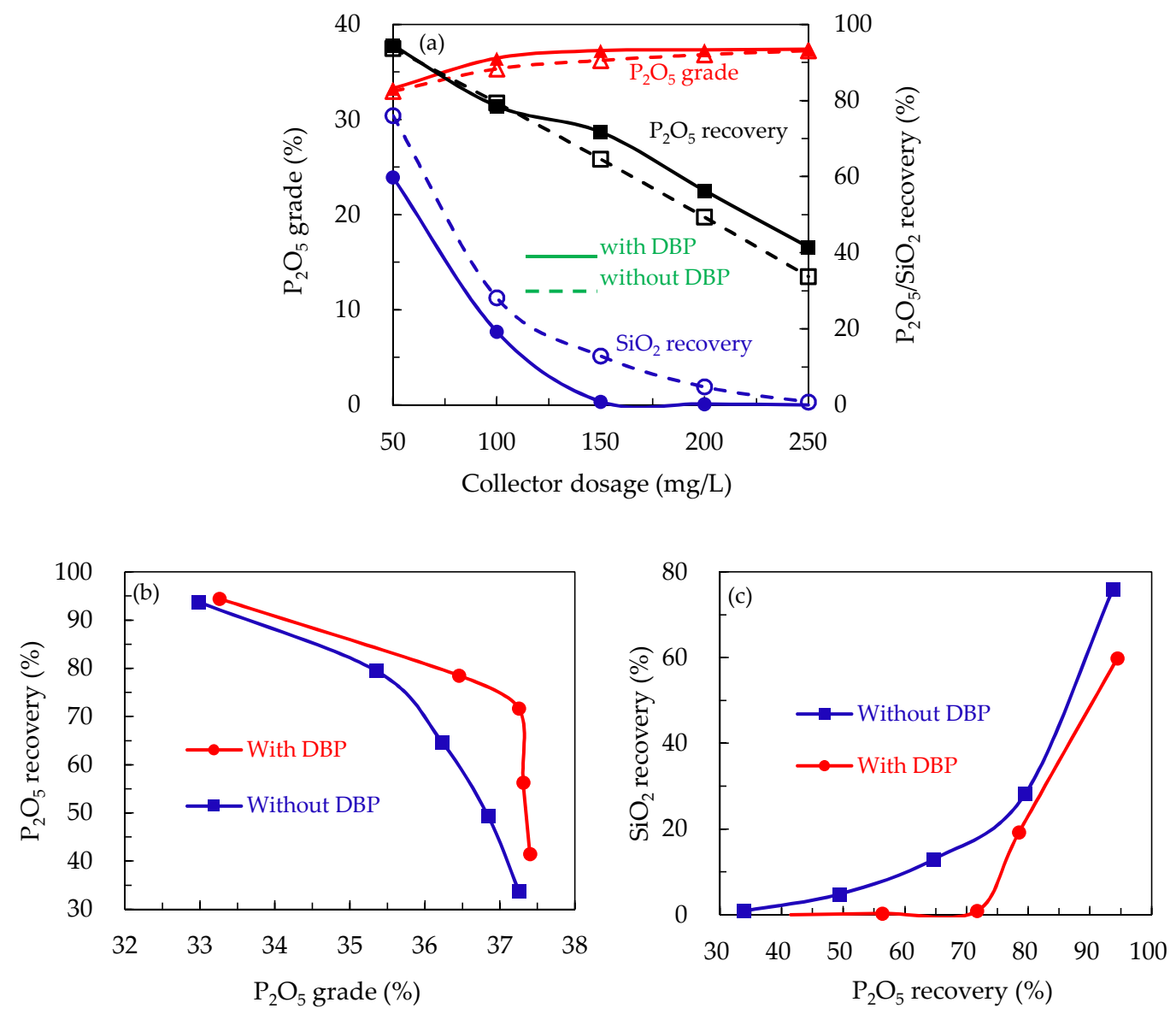

Figure 3. Effect of $\mathrm{CTAB}$ concentration on flotation performance of quartz and collophane mixture at $\mathrm{pH}$ 6.0. (a) $\mathrm{P}_{2} \mathrm{O}_{5}$ grade, $\mathrm{SiO}_{2}$ and $\mathrm{P}_{2} \mathrm{O}_{5}$ recovery as a function of collector dosage with and without DBP; (b) $\mathrm{P}_{2} \mathrm{O}_{5}$ recovery as a function of $\mathrm{P}_{2} \mathrm{O}_{5}$ grade with and without $\mathrm{DBP}$; (c) $\mathrm{SiO}_{2}$ recovery as a function of $\mathrm{P}_{2} \mathrm{O}_{5}$ recovery with and without DBP. 
The results shown in Figure $3 \mathrm{a}$ indicate that concentrate $\mathrm{P}_{2} \mathrm{O}_{5}$ grade increased slightly but concentrate $\mathrm{P}_{2} \mathrm{O}_{5}$ recovery and $\mathrm{SiO}_{2}$ recovery decreased significantly with increasing CTAB concentration with or without DBP. For example, in the presence of DBP the $\mathrm{P}_{2} \mathrm{O}_{5}$ recovery decreased from more than $94.5 \%$ to $41.5 \%$ as the CTAB dosage increased from 50 to $250 \mathrm{mg} / \mathrm{L}$ and the $\mathrm{SiO}_{2}$ recovery decreased from $59.9 \%$ to 0 with the CTAB dosage increasing from 50 to $150 \mathrm{mg} / \mathrm{L}$. In the absence of DBP, a similar trend was observed with $\mathrm{P}_{2} \mathrm{O}_{5}$ recovery but the decrease in $\mathrm{SiO}_{2}$ recovery was more gradual with increasing CTAB dosage. In fact, the complete rejection of $\mathrm{SiO}_{2}$ from collophane was not accomplished until the CTAB dosage reached $250 \mathrm{mg} / \mathrm{L}$ in the absence of DBP. Regardless of the presence of DBP the three performance indicators shown in Figure 3a showed strong dependence on the CTAB concentration, which is consistent with previous studies $[6,10,28]$. Li et al. [6] and Huang et al. [10] showed that the concentrate $\mathrm{P}_{2} \mathrm{O}_{5}$ grade increased and the recovery of $\mathrm{P}_{2} \mathrm{O}_{5}$ and $\mathrm{SiO}_{2}$ decreased with increasing collector dosage in the reverse flotation of phosphate. This is because in the reverse flotation of collophane the higher dosage of collector for quartz would inevitably increase its adsorption on the collophane particles as well as on the composite particles that contain collophane. As a result, more collophane particles and composite particles will remove to the froth product, reducing its recovery in the collophane concentrate, which tends to have some positive effects on the collophane concentrate grade.

The effects of DBP on the flotation separation of quartz from collophane by CTAB can be revealed by comparing the flotation performance produced with and without DBP. Figure $3 \mathrm{a}$ indicates that both $\mathrm{P}_{2} \mathrm{O}_{5}$ grade and $\mathrm{P}_{2} \mathrm{O}_{5}$ recovery obtained in the presence of DBP was substantially higher than that generated in the absence of DBP at the same CTAB concentration and the $\mathrm{SiO}_{2}$ recovery was lower in the presence of DBP than in the absence of DBP. For example, at a CTAB concentration of $150 \mathrm{mg} / \mathrm{L} \mathrm{a} \mathrm{P}_{2} \mathrm{O}_{5}$ recovery of $71.7 \%$ and no quartz recovery were observed in the presence of DBP whereas the concentrate $\mathrm{P}_{2} \mathrm{O}_{5}$ recovery and $\mathrm{SiO}_{2}$ recovery were $64.6 \%$ and $12.9 \%$ without DBP. A further increase in the CTAB concentration to $250 \mathrm{mg} / \mathrm{L}$ decreased the concentrate $\mathrm{SiO}_{2}$ recovery to nearly zero in the absence of DBP. In other words, the use of DBP increased concentrate $\mathrm{P}_{2} \mathrm{O}_{5}$ recovery and decreased concentrate $\mathrm{SiO}_{2}$ recovery, resulting in a significant improvement of separation efficiency and concentrate $\mathrm{P}_{2} \mathrm{O}_{5}$ grade.

To better compare the flotation separation efficiency obtained with and without DBP, the concentrate $\mathrm{P}_{2} \mathrm{O}_{5}$ recovery was replotted as a function of concentrate $\mathrm{P}_{2} \mathrm{O}_{5}$ grade in Figure $3 b$ while the concentrate $\mathrm{SiO}_{2}$ recovery is replotted against $\mathrm{P}_{2} \mathrm{O}_{5}$ recovery in Figure $3 \mathrm{c}$. It is obvious from Figure $3 b$ that the $\mathrm{P}_{2} \mathrm{O}_{5}$ recovery was always higher at a given $\mathrm{P}_{2} \mathrm{O}_{5}$ grade with $\mathrm{DBP}$ than without DBP, suggesting that the use of DBP enhanced flotation efficiency. Figure $3 \mathrm{c}$ clearly shows that the $\mathrm{SiO}_{2}$ recovery was always lower at a given $\mathrm{P}_{2} \mathrm{O}_{5}$ recovery in the presence of $\mathrm{DBP}$, indicating that the use of DBP improved $\mathrm{SiO}_{2}$ removal from collophane. Figure $3 b, c$ clearly show that that the use of DBP resulted in a more efficient separation of quartz from collophane in weakly acidic conditions which are strongly preferred by the industry.

\subsection{Effect of DBP on Surface Tension}

Solution surface tension is an important parameter in mineral flotation. The effect of DBP on surface tension is shown in Figure 4 for different CTAB concentrations. It can be seen from Figure 4 that the surface tension rapidly decreased on increasing the CTAB concentration in the presence and absence of DBP. In the absence of DBP, the critical micelle concentration of the CTAB solution was about $100 \mathrm{mg} / \mathrm{L}$ at which the surface tension was $40.9 \mathrm{mN} / \mathrm{m}$. For the mixed CTAB and DBP solution, the CMC and $\gamma_{\mathrm{CMC}}$ values were reduced to $50 \mathrm{mg} / \mathrm{L}$ and $28.7 \mathrm{mN} / \mathrm{m}$, indicating that the addition of DBP enhanced the micelle formation capacity and increased the surface activity.

Chen et al. [29] showed that the addition of $\alpha$-terpineol further reduced surface tension compared to the salicylhydroxamic acid or methyl isobutyl carbinol system and resulted in an additional reduction in bubble size. Sobhy et al. [12] and Tao and Sobhy [13] demonstrated that the bubble diameter had a significant impact on the bubble-particle 
collision and attachment efficiency and that the collision efficiency increased with decreasing bubble diameter. This flotation improvement mechanism is particularly important for fine and ultrafine quartz particles for which the collision efficiency is the flotation rate determining parameter.

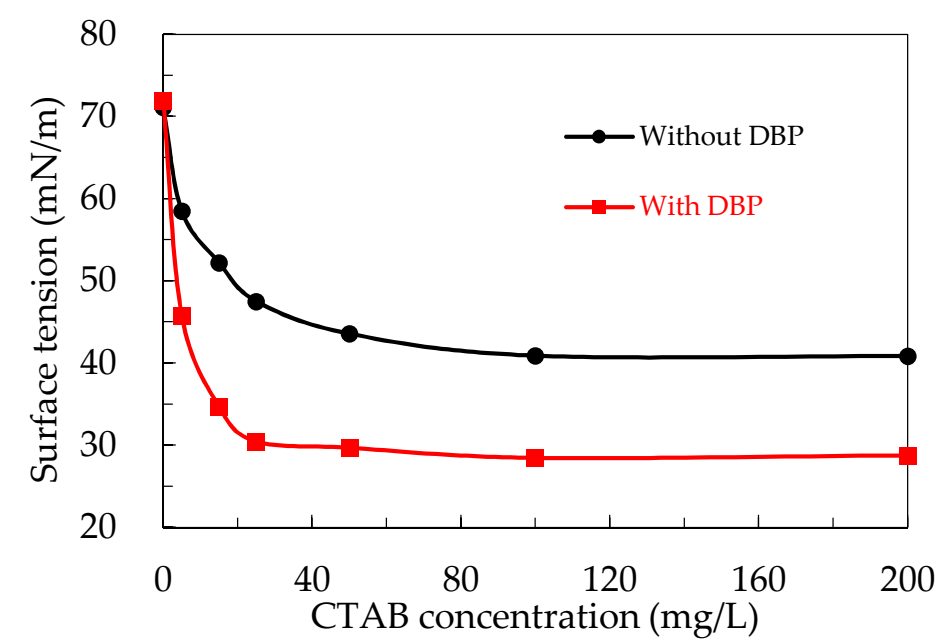

Figure 4. Effects of $\mathrm{CTAB}$ concentration on solution surface tension at $\mathrm{pH} 6.0$ without $\mathrm{DBP}$ and with $\mathrm{DBP}$ at a DBP/CTAB mass ratio of 1:5.

\subsection{DBP-Assisted Aggregation of Quartz Particles}

The effect of CTAB and DBP on the agglomeration of quartz particles is shown in Figure 5 where the black curve represents the original size distribution of the quartz particles with the characteristic $\mathrm{d}_{50}, \mathrm{~d}_{90}$, and $\mathrm{d}_{97}$ being $84.8 \mu \mathrm{m}, 135.6 \mu \mathrm{m}$, and $163.2 \mu \mathrm{m}$, respectively. The size distribution curve in the presence of $5 \mathrm{mg} / \mathrm{L} \mathrm{CTAB}$ (shown in green) was essentially identical to the original one. However, in the dual presence of $1 \mathrm{mg} / \mathrm{L}$ DBP and $5 \mathrm{mg} / \mathrm{LCTAB}$, the size distribution curve (shown in red) was shifted significantly to the right with the $d_{50}, d_{90}$, and $d_{97}$ increased to $100.6 \mu \mathrm{m}, 176.0 \mu \mathrm{m}$, and $222.3 \mu \mathrm{m}$, respectively, indicating that the synergestic effect of $\mathrm{CTAB}$ and $\mathrm{DBP}$ resulted in significant aggregation of quartz particles. It should be noted that particle size analysis was performed with the pretreated reagents to exclude the influence of DBP droplets on the agglomerate particle size. The analysis results showed that the $\mathrm{D}_{50}$ and $\mathrm{D}_{90}$ of DBP droplets were $3.58 \mu \mathrm{m}$ and $9.80 \mu \mathrm{m}$, respectively, which are similar to the emulsion droplets of dodecane, oleic acid and their mixtures tested by Liao et al. [30]. It could be concluded that the addition of DBP had minimal effect on the measurements results of aggregate size.

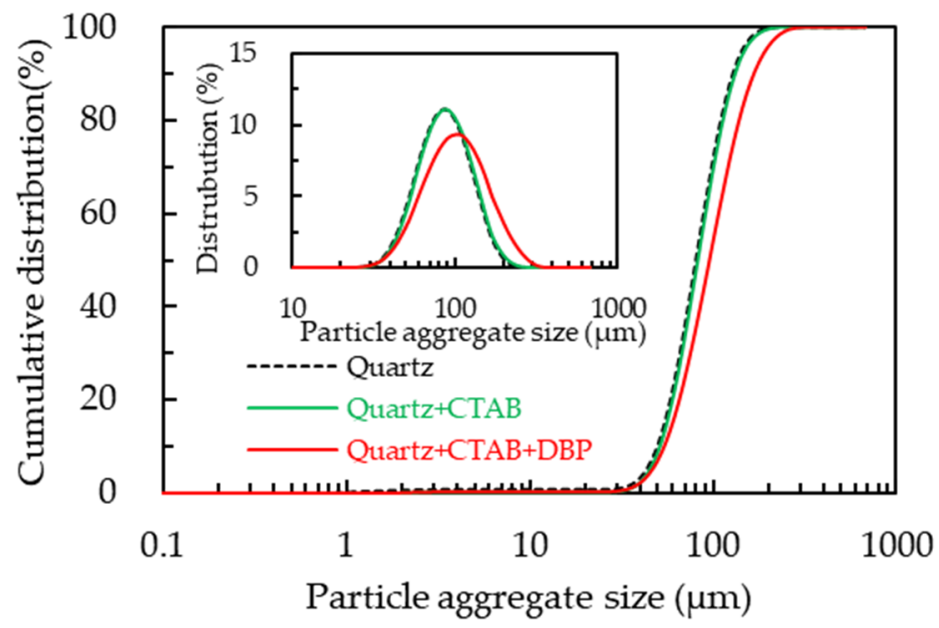

Figure 5. Aggregation states of quartz particles with and without DBP. 
Different from polar collectors, non-polar oils and esters can only be adsorbed on the hydrophobic mineral surface by intermolecular forces and their adsorption in turn makes the mineral surface more hydrophobic [23]. Li et al. [16] investigated the effect of non-polar oil on fine hematite flocculation and flotation using sodium oleate or hydroxamic acids as collector and reported that the addition of kerosene further enhanced the aggregate size due to the strong hydrophobic interaction between the hydrophobic fine hematite particles and kerosene droplets. Ozkan et al. [17] studied the role of non-polar oils and ester compounds in particle aggregation in the flotation system and concluded that they enhanced the aggregation of hydrophobic particles through a bridging mechanism after spreading on the particle surfaces. Liu et al. [31] demonstrated that the large compact agglomerates formed by use of the combined DDA-kerosene collector improved the flotation performance of fine quartz particles.

Depending on how CTAB and DBP are added to the pulp, there are multiple modes of interactions between the reagent molecules and the quartz particles. First, if only CTAB is added to the pulp, the CTAB molecules will be directly adsorbed onto the quartz particles through electrostatic attraction [8,27], as shown in Figure 6a. Cao et al. [32] reported that the addition of polyglycol decreased the interfacial tension between dodecane and water. Liu et al. [31] concluded that the hydrocarbon chain of DDA was preferentially oriented toward the oil droplets upon adsorption on quartz and the polar head was located at the oil-water interface towards the water phase. Second, if CTAB and DBP are mixed together prior to addition to the pulp, CTAB molecules may be adsorbed on the DBP droplets at the DBP-water interface with the hydrocarbon chain of CTAB extended into the DBP droplets and its polar head exposed to the solution. The CTAB coated DBP droplets can be adsorbed on to quartz particles initially by means of physical adsorption and the bonding affinity can be subsequently strengthened by the strong hydrophobic interactions between nonpolar DBP molecules and the hydrocarbon chains of the CTAB molecules, greatly enhancing the aggregation, as shown in Figure $6 \mathrm{~b}$. Third, if CTAB is added to the pulp first followed by the addition of DBP, the DBP droplets will serve as the bridge between CTAB adsorbed quartz particles, forming DBP strengthened aggregates, as shown in Figure 6c. Liu et al. [31] investigated the roles of DDA and kerosene in quartz aggregation and proposed a similar aggregation mechanism.

(a)

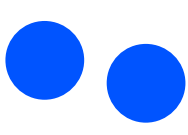

Quartz

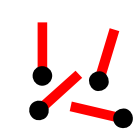

CTAB

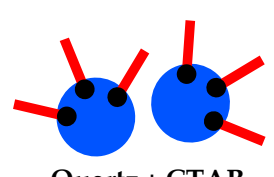

Quartz + CTAB

(b)

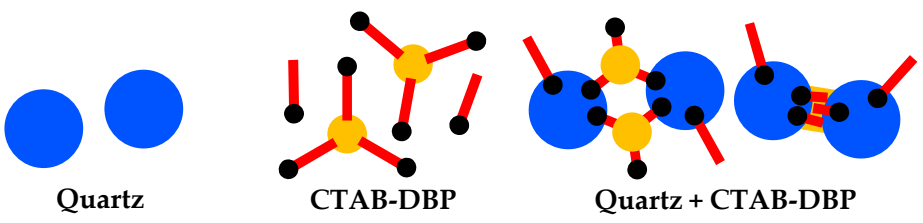

(c)

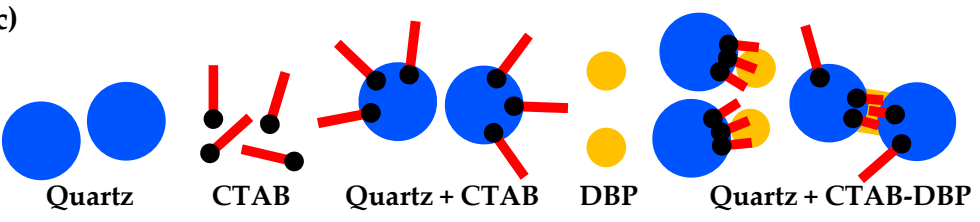

Figure 6. Schematic representation of interactions between quartz and CTAB (a), CTAB-DBP (b), CTAB and DBP (c).

The mechanisms of flotation performance improvement by DBP-assisted aggregation of quartz particles can be understood from two aspects. On the one hand, the adhesion of DBP on the surface of quartz particles significantly enhances the surface hydrophobicity, 
thus improving the difference in floatability between quartz and collophane. On the other hand, DBP-assisted aggregation has a significant impact on the apparent size of quartz particles. The collection probability of mineral particles by bubbles is dependent on many factors in the flotation process, particularly the particle size, hydrophobicity, and bubble size, etc. [13]. Ma et al. [33] investigated nanobubble enhanced column flotation of Chinese sub-bituminous coal and concluded that enhancing mineral surface hydrophobicity and increasing apparent particle size were effective ways to improve the collection probability.

\subsection{Effect of DBP on Entrainment in Froth}

The non-selective hydraulic entrainment of fine collophane particles in froth significantly influences the flotation separation performance and should be minimized to obtain optimum separation. Flotation tests were performed with and without DBP at different $\mathrm{CTAB}$ concentrations to quantify the effect of DBP on froth characteristics. Figure 7 shows water mass fraction and water recovery (defined as the percentage of pulp water that reports to the froth product) in the froth product as a function of CTAB concentration. Both parameters can be used to characterize froth stability but the water mass fraction is a direct measure of froth wetness and water recovery is more strongly dependent on the amount of froth product. The fact that the water mass fraction and water recovery curves are nearly parallel, with and without DBP, suggests that these two parameters are strongly correlated. Data shown in Figure 7 indicate that higher CTAB concentration results in a more stable froth and consequently more significant entrainment. In the absence of DBP, water mass fraction and water recovery increased from $39.5 \%$ and $0.7 \%$ to $71.4 \%$ and $16.1 \%$, respectively with increasing CTAB concentration from 50 to $250 \mathrm{mg} / \mathrm{L}$. In the presence of DBP, water mass fraction and water recovery gradually increased from $29.1 \%$ and $0.4 \%$ to $37.7 \%$ and $4.3 \%$, respectively over the same range of CTAB concentration. Obviously, the use of DBP not only reduced the water mass fraction and recovery at a given CTAB concentration but also reduced the rate of increase of both parameters with increase in $\mathrm{CTAB}$ concentration. As a result, the effect of DBP on froth stability was more pronounced at higher CTAB dosages. The data shown in Figure 7 clearly indicates that DBP can be used to effectively control froth stability and minimize the hydraulic entrainment in the froth product.

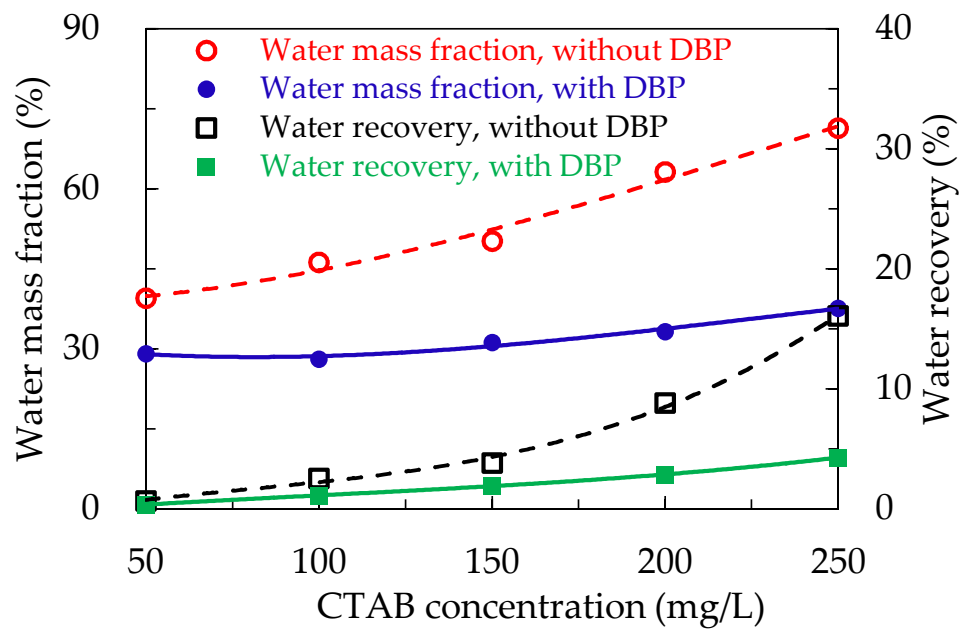

Figure 7. Water mass fraction and water recovery in froth product as a function of CTAB concentration with and without DBP.

It is believed that the impact of DBP on froth stability is closely related to its bridging agglomeration effect on quartz particles shown in Figures 5 and 6. Yan et al. [34] studied oil film spreading on the surface of a bubble and concluded that the original water film on the bubble can be replaced by the oil film during the flotation process. Consequently, 
hydrophobic interactions occur between DBP-coated bubbles and hydrophobic aggregates of quartz, further enhancing the bubble mineralization process. As mineralized bubbles ascend in the froth, the hydrophobic attraction promotes liquid drainage, resulting in more rapid thinning of the liquid lamellae between them. In contrast, the hydrophobic particles on the surface of the mineralized bubbles show electrostatic repulsion in the absence of DBP, hindering lamellae thinning.

Froths of different water mass fractions have significant implications for flotation performance. With a wet froth its water mass fraction is high and a large number of fine collophane particles are entrained within the liquid lamellae and in the plateau-area surrounded by neighboring bubbles. Hoang et al. [35] claimed that the negative rheological effects within the pulp led to more serious nonselective hydraulic entrainment of fine particles than coarse particles, due to the smaller momentum of fine particles. Therefore, it can be concluded that more of the fine collophane particles are entrained in the wet froth product. Wu and Tao [14] provided evidence with actual mineral flotation that the fine dissemination size of collophane particle, the poor degree of mineral liberation, and the serious slime generation were the main reasons for poor flotation performance with collophane which was exemplified by the fact that $4.74 \%$ liberated collophane particles of less than $30 \mu \mathrm{m}$ were lost to the siliceous tailings in the closed-circuit double reverse desilication flotation process with a rougher scavenger and two stages. With a dry froth its water mass fraction is low, less liquid exists in the lamellae and plateau-areas. In addition, a significant bubble surface area reduction caused by rapid bubble coalescence in the dry froth will result in competition for the bubble surface among different particles and the less hydrophobic collophane particles are more likely to get detached from the bubble surface, resulting in a secondary cleaning effect of the froth, which will have a positive impact on the flotation separation performance.

The effect of non-polar substances on froth behavior has been investigated by other researchers. Zhou et al. [36] showed that the presence of emulsified kerosene in the form of droplets with an average diameter of $700 \mathrm{~nm}$ enhanced the hydrophobicity of froth and intensified the coalescence of bubbles. Consequently, the stability of the bubbles deteriorated, and the water mass fraction of the froth decreased, reducing the entrainment of fine collophane particles during the flotation process. Xu et al. [37] further proved through a single foam film drainage experiment that the introduction of excessive diesel made diesel oil droplets disperse into the middle of the foam film, resulting in the formation of an oil bridge and rupture of the foam film. Meanwhile, the oil film spreading pressure increased with the increase of diesel concentration and diesel oil droplets competed with froth molecules for adsorption, which reduced the effective concentration of froth at the gas-water interface. The above findings explain well the mechanism of reducing the entrainment of fine collophane particles by promoting defoaming and liquid lamellae thinning, thus reducing the recovery of collophane (Figure 2b) and increasing the concentrate $\mathrm{P}_{2} \mathrm{O}_{5}$ recovery (Figure 3). Consequently, a higher flotation separation efficiency can be obtained by overcoming the defoaming difficulties associated with the traditional amine collectors used for desilication of collophane.

\section{Conclusions}

This study demonstrated that the addition of DBP in the reverse flotation of collophane with $\mathrm{CTAB}$ used as collector, exhibited an excellent synergistic effect on the separation of quartz from collophane. Based on the above results and discussion, the following conclusions can be drawn:

- The use of DBP in reverse flotation of collophane significantly improved the collecting potency and selectivity of CTAB for quartz at all $\mathrm{pH}^{\prime}$ and $\mathrm{CTAB}$ concentrations examined.

- Concentrate $\mathrm{P}_{2} \mathrm{O}_{5}$ grade and recovery obtained in the presence of DBP was substantially higher than that generated in the absence of DBP at the same CTAB concentration. 
- The addition of DBP reduced the solution surface tension and the bubble size and improved the collision efficiency between the bubbles and the quartz particles.

- DBP improved the aggregation behavior of the coarse and fine quartz particles due to the strong hydrophobic interaction between the hydrophobic quartz particles and DBP droplets with stronger affinity for the quartz surface than for kerosene droplets.

- The introduction of DBP at a suitable dosage promoted defoaming and reduced the hydraulic entrainment of fine collophane particles.

Author Contributions: Conceptualization, D.T. and P.Z.; methodology, Z.W.; validation, X.J.; investigation, Z.W.; resources, X.J.; data curation, Z.W.; writing-original draft preparation, Z.W.; writing-review and editing, D.T. and P.Z.; supervision, D.T. and M.J.; funding acquisition, D.T. All authors have read and agreed to the published version of the manuscript.

Funding: This research was funded by the Natural Science Foundation of China, grant number 51804188 .

Acknowledgments: The authors acknowledge the support of the Yunnan Yuntianhua Co., Ltd. that provided the phosphate samples.

Conflicts of Interest: The authors declare that they have no known competitive financial interests or personal relationships, which could affect the work reported in this paper.

\section{References}

1. Abouzeid, A.Z.M. Physical and thermal treatment of phosphate ores-An overview. Int. J. Miner. Process. 2008, 85, 59-84. [CrossRef]

2. Ministry of Natural Resources. China Mineral Resources; Geological Publishing House: Beijing, China, 2012; pp. 52-60. (In Chinese)

3. Liu, X.; Li, C.X.; Luo, H.H.; Cheng, R.J.; Liu, F.Y. Selective reverse flotation of apatite from dolomite in collophanite ore using saponified gutter oil fatty acid as a collector. Int. J. Miner. Process. 2017, 165, 20-27. [CrossRef]

4. Sis, H.; Chander, S. Reagents used in the flotation of phosphate ores: A critical review. Miner. Eng. 2003, 16, 577-585. [CrossRef]

5. Yang, H.Y.; Xiao, J.F.; Xia, Y.; Xie, Z.J. Origin of the Ediacaran Weng'an and Kaiyang phosphorite deposits in the Nanhua basin, SW China. J. Asian Earth Sci. 2019, 182, 103931. [CrossRef]

6. Li, X.B.; Zhang, Q.; Hou, B.; Ye, J.J; Mao, S.; Li, X.H. Flotation separation of quartz from collophane using an amine collector and its adsorption mechanisms. Powder Technol. 2017, 318, 224-229. [CrossRef]

7. Wu, Z.X.; Tao, D.P.; Jiang, X.J. Experimental Study on a Novel Cationic Collector for Reverse Flotation of Collophane for Silica Removal. Multipurp. Util. Miner. Resour. 2020, 5, 92-100. (In Chinese)

8. Fang, J.; Ge, Y.Y.; Yu, J. Adsorption behavior and mechanism of an ether amine collector on collophane and quartz. Physicochem. Probl. Miner. Process. 2019, 55, 301-310. [CrossRef]

9. Han, Y.; Han, S.; Kim, B.; Yang, J. Flotation separation of quartz from apatite and surface forces in bubble-particle interactions: Role of $\mathrm{pH}$ and cationic amine collector contents. J. Ind. Eng. Chem. 2019, 70, 107-115. [CrossRef]

10. Huang, Z.Q.; Cheng, C.; Liu, Z.W.; Zeng, H.Q.; Feng, B.; Zhong, H.; Luo, W.H.; Hu, Y.J.; Guo, Z.Q.; He, G.C.; et al. Utilization of a new Gemini surfactant as the collector for the reverse froth flotation of phosphate ore in sustainable production of phosphate fertilizer. J. Clean. Prod. 2019, 221, 108-112. [CrossRef]

11. Vieira, A.M.; Peres, A.E.C. The effect of amine type, $\mathrm{pH}$, and size range in the flotation of quartz. Miner. Eng. 2007, 20, 1008-1013. [CrossRef]

12. Sobhy, A.; Wu, Z.X.; Tao, D.P. Statistical analysis and optimization of reverse anionic hematite flotation integrated with nanobubbles. Miner. Eng. 2020, 163, 106799. [CrossRef]

13. Tao, D.P.; Wu, Z.X.; Sobhy, A. Investigation of nanobubble enhanced reverse anionic flotation of hematite and associated mechanisms. Powder Technol. 2020, 379, 12-25. [CrossRef]

14. Wu, Z.X.; Tao, D.P. Mineralogical analysis of collophane in Yunnan using AMICS and exploration of difficult flotation mechanisms. Chin. J. Eng. 2021, 43, 503-511. (In Chinese) [CrossRef]

15. Xia, Y.C.; Zhang, R.; Xing, Y.W.; Gui, X.H. Improving the adsorption of oily collector on the surface of low-rank coal during flotation using a cationic surfactant: An experimental and molecular dynamics simulation study. Fuel 2019, 235, 687-695. [CrossRef]

16. Li, H.; Liu, M.X.; Liu, Q. The effect of non-polar oil on fine hematite flocculation and flotation using sodium oleate or hydroxamic acids as a collector. Miner. Eng. 2018, 119, 105-115. [CrossRef]

17. Ozkan, A.; Dudnik, V.; Esmeli, K. Hydrophobic flocculation of talc with kerosene and effects of anionic surfactants. Part. Sci. Technol. 2015, 34, 235-240. [CrossRef]

18. Liu, A.; Fan, M.Q.; Li, Z.H.; Fan, J.C. Non-polar oil assisted DDA flotation of quartz I: Interfacial interaction between dodecane oil drop and mineral particle. Int. J. Miner. Process. 2017, 168, 1-8. [CrossRef] 
19. Qiao, X.X.; Liu, A.; Li, Z.H.; Fan, J.C.; Luo, C.J.; Fan, P.P.; Liu, Y.Z.; Fan, M.Q. A novel miscible collector DDA-2-octanol-kerosene: Properties and flotation performance. Miner. Eng. 2020, 156, 106475. [CrossRef]

20. Nazari, S.; Shafaei, S.Z.; Gharabaghi, M.; Ahmadi, R.; Shahbazi, B.; Fan, M.M. Effects of nanobubble and hydrodynamic parameters on coarse quartz flotation. Int. J. Min. Sci. Technol. 2019, 29, 289-295. [CrossRef]

21. Lin, D.; Zhong, J.M.; Ji, S.M.; Yuan, Z.X.; Xing, L.J.; He, Q.; Zhang, H.L.; Huo, Y.P. Highly efficient triplet-triplet annihilation upconversion in high viscosity phthalate ester media. Dye. Pigment. 2021, 185, 108912. [CrossRef]

22. Liao, Y.F.; Yang, Z.; An, M.Y.; Cao, Y.J.; Hao, X.D.; Song, X.W.; Ren, H.R.; Yang, A.S.; Chen, L.J. Spreading behavior of dodecaneoleic acid collector mixture in low-rank coal flotation. Fuel 2022, 308, 122071. [CrossRef]

23. Tan, J.L.; Cheng, H.Z.; Wei, L.B.; Gui, X.H.; Xing, Y.W. Investigation of CTAB and DBP esters on low-rank coal flotation selectivity. Energe Source Part A 2019, 42, 1-10. [CrossRef]

24. Li, C.; Cao, Y.J.; Peng, W.J.; Shi, F.N. On the correlation between froth stability and viscosity in flotation. Miner. Eng. 2020, 149, 106269. [CrossRef]

25. Li, C.; Runge, K.; Shi, F.N.; Farrokhpay, S. Effect of flotation froth properties on froth rheology. Powder Technol. 2016, 294, 55-65. [CrossRef]

26. Yang, Z.C.; Teng, Q.; Liu, J.; Yang, W.P.; Hu, D.H.; Liu, S.Y. Use of NaOL and CTAB mixture as collector in selective flotation separation of enstatite and magnetite. Colloids Surf. A Physicochem. Eng. Asp. 2019, 570, 481-486. [CrossRef]

27. Carvalho, J.A.E.D.; Brando, P.; Henriques, A.B.; Oliveira, P.S.D.; Cançado, R.Z.L.; Silva, G.R.D. Selective flotation of apatite from micaceous minerals using patauá palm tree oil collector. Miner. Eng. 2020, 156, 106474. [CrossRef]

28. Xu, T.H.; Long, B.W.; Zhang, Y.; Deng, F.L.; Dai, Y.F.; Zhang, L.L.; Ding, Y.G. Synthesis and Application of Silicon Removal Reagent for Reverse Flotation of Phosphate Rock. Multipurp. Util. Miner. Resour. 2021, 3, 57-63. (In Chinese)

29. Chen, Y.M.; Li, H.; Feng, D.X.; Tong, X.; Hu, S.X.; Yang, F.; Wang, G.C. A recipe of surfactant for the flotation of fine cassiterite particles. Miner. Eng. 2021, 160, 106658. [CrossRef]

30. Liao, Y.F.; Hao, X.D.; An, M.Y.; Yang, L.F.; Ren, H.R. Enhancing low-rank coal flotation using mixed collector of dodecane and oleic acid: Effect of droplet dispersion and its interaction with coal particle. Fuel 2020, 280, 118634. [CrossRef]

31. Liu, A.; Fan, M.Q.; Fan, P.P. Interaction mechanism of miscible DDA-Kerosene and fine quartz and its effect on the reverse flotation of magnetic separation concentrate. Miner. Eng. 2014, 65, 41-50. [CrossRef]

32. Cao, L.; Chen, X.M.; Peng, Y.J. The effect of polyglycol-type frothers on the interfacial characteristics of oily collector dispersion. Miner. Eng. 2020, 157, 106579. [CrossRef]

33. Ma, F.Y.; Tao, D.P.; Tao, Y.J. Effects of nanobubbles in column flotation of Chinese sub-bituminous coal. Int. J. Coal Prep. Util. 2019, 1-17. [CrossRef]

34. Yan, S.L.; Yang, X.Y.; Bai, Z.S.; Xu, X.; Wang, H.L. Drop attachment behavior of oil droplet-gas bubble interactions during flotation. Chem. Eng. Sci. 2020, 223, 115740. [CrossRef]

35. Hoang, D.H.; Hassanzadeh, A.; Peuker, U.A.; Rudolph, M. Impact of flotation hydrodynamics on the optimization of fine-grained carbonaceous sedimentary apatite ore beneficiation. Powder Technol. 2019, 345, 223-233. [CrossRef]

36. Zhou, S.Q.; Wang, X.X.; Bu, X.N.; Shao, H.Z.; Hu, Y.; Alheshibri, M.; Li, B.; Chao, N.; Peng, Y.L.; Xie, G.Y. Effects of emulsified kerosene nanodroplets on the entrainment of gangue materials and selectivity index in aphanitic graphite flotation. Miner. Eng. 2020, 158, 106592. [CrossRef]

37. Xu, M.D.; Xing, Y.W.; Jin, W.; Li, M.; Cao, Y.J.; Gui, X.H. Effect of diesel on the froth stability and its antifoam mechanism in fine coal flotation used MIBC as the frother. Powder Technol. 2019, 364, 183-188. [CrossRef] 